\title{
Evaluation of Ruxolitinib versus Best Available Therapy in Treating Primary Myelofibrosis
}

"Kawa M. Hasan, ${ }^{1,2}$ Ahmed Y. Elmeshhadany, ${ }^{1,2}$ Nazar P. Shabila ${ }^{3}$

\begin{abstract}
Objectives: This study aimed to evaluate the effectiveness of ruxolitinib and compare it with the best available therapy in patients with primary myelofibrosis. Ruxolitinib is a Janus kinase inhibitor that is approved for the treatment of myelofibrosis. The therapeutic protocol has changed after the introduction of ruxolitinib. Methods: In this retrospective study, 72 patients with primary myelofibrosis were scrutinised from January 2012 to January 2018 at Nanakali Hemato-Oncology Teaching Centre in Erbil, Iraqi Kurdistan. The patients were divided into two cohorts: 26 of them were treated with ruxolitinib and 46 received the best available therapy. The patients' characteristics, their response to the treatment and the outcomes were evaluated. The efficacy of the treatment in both groups was compared. Results: Most patients $(\mathrm{n}=46 ; 63.9 \%)$ were in the high and intermediate-2 risk groups according to the international prognostic scoring system. At the time of diagnosis, no noticeable differences in the clinical characteristics and laboratory data were observed among the ruxolitinib and best available treatment groups. Ruxolitinib was found to be effective in reducing the size of the spleen and improving the overall survival rate when compared to the best available treatment group $(P<0.001$ and $P=0.008$, respectively). The patients' performance status had a significant effect on the overall survival in both treatment groups $(P=0.003)$. Conclusion: Ruxolitinib appears to have a significant role in reducing the spleen size and potentially affect the survival outcomes in patients with myelofibrosis.
\end{abstract}

Keywords: Ruxolitinib; Myelofibrosis; Splenomegaly; Janus Kinase Inhibitor; Iraq.

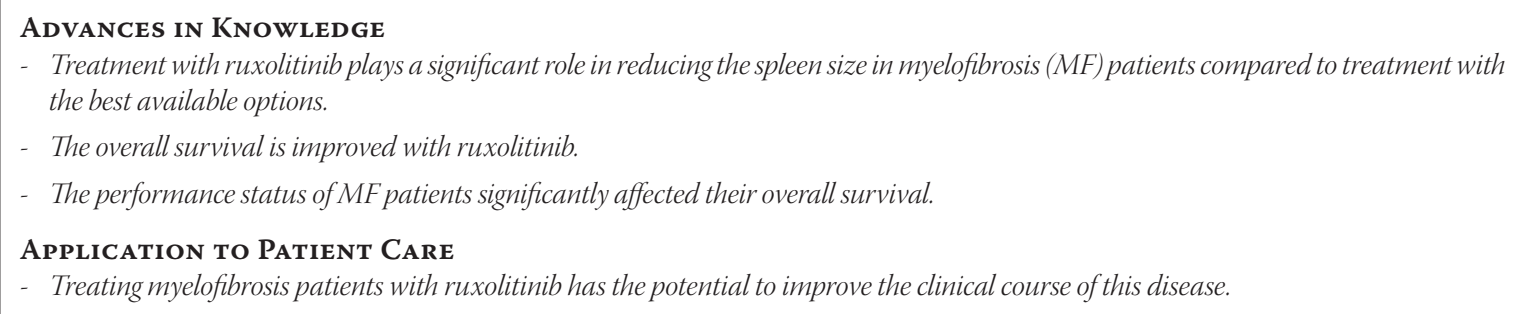

$\mathrm{M}$ YELOFIBROSIS (MF) IS A MYELOPROLIFerative neoplasm that is characterised by somatic mutation of the haematopoietic stem cells, which leads to overactive signalling through the Janus kinase-signal transducer and activator of transcription (JAK-STAT) pathway as the central pathogenic mechanism. ${ }^{1}$ MF could be primary, secondary to polycythaemia vera (post-PV MF) or essential thrombocythemia (post-ET MF). ${ }^{2}$ The principal genetic drivers in most MF patients are the Janus kinase 2 (JAK2), MPL proto-oncogene, thrombopoietin receptor $(M P L)$ and calreticulin $(C A L R)$ mutations that contribute to the pathophysiology of the disease; additionally, almost half of the patients carry a mutation in the JAK2 gene (JAK2 V617F).,34 The characteristic clinical features of MF are constitutional symptoms such as fatigue, bone pain, weight loss and a hypercatabolic state. MF is also associated with cytopaenia (especially progressive anaemia), splenomegaly, bone marrow fibrosis, leukoerythroblastosis in the peripheral blood, poor quality of life and shortened survival. ${ }^{4,5}$
Patients with MF are categorised into different risk groups based on the presence of the following five adverse prognostic factors at the time of diagnosis: (i) age >65 years; (ii) haemoglobin $(\mathrm{Hb})<10 \mathrm{~g} / \mathrm{dL}$; (iii) white blood cell (WBC) count $>25 \times 10^{9} / \mathrm{L}$; (iv) blood blasts $\geq 1 \%$; and (v) constitutional symptoms. Depending on the number of these adverse risk factors, MF patients are grouped into one of four groups according to the International Prognostic Scoring System (IPSS) or Dynamic IPSS (DIPSS): low risk, intermediate risk-1, intermediate risk-2 and high risk. ${ }^{6}$ The estimated median survival of patients after primary MF diagnosis ranges from 2.25 to 11.25 years, depending on the risk level. ${ }^{6}$

Although the therapeutic outlines have been changed after the introduction of ruxolitinib as a Janus kinase $(J A K)$ inhibitor, allogeneic stem cell transplantation (allo-SCT) remains the only curative therapy; however, allo-SCT is applicable for a minority of patients. The other forms of conventional treatments include using erythropoiesis-stimulating agents, immunomodulatory agents or androgen 
Table 1: Characteristics of patients with primary myelofibrosis at the time of diagnosis $(\mathrm{N}=72)$

\begin{tabular}{|c|c|c|c|}
\hline \multirow[t]{2}{*}{ Characteristic } & \multicolumn{2}{|c|}{ n (\%) } & \multirow{2}{*}{$\begin{array}{c}P \\
\text { value* }\end{array}$} \\
\hline & Ruxolitinib & BAT & \\
\hline $\begin{array}{l}\text { Mean age in } \\
\text { years }\end{array}$ & $58.1 \pm 12.03$ & $60.7 \pm 12.61$ & 0.400 \\
\hline Gender & & & 0.723 \\
\hline Male $(\mathrm{n}=38)$ & $13(34.2)$ & $25(65.8)$ & \\
\hline Female $(\mathrm{n}=34)$ & $13(38.2)$ & $21(61.8)$ & \\
\hline $\begin{array}{l}\text { Median time } \\
\text { of follow-up in } \\
\text { months }\end{array}$ & 55.2 & 36 & \\
\hline IPSS & & & 0.390 \\
\hline High risk & $11(42.3)$ & $15(57.7)$ & \\
\hline Intermediate- 2 & $6(30.0)$ & $14(70.0)$ & \\
\hline Intermediate-1 & $7(46.7)$ & $8(53.3)$ & \\
\hline Low risk & $2(18.2)$ & $9(81.8)$ & \\
\hline ECOG-PS score & & & 0.900 \\
\hline 0 & $2(40.0)$ & $3(60.0)$ & \\
\hline 1 & $13(38.2)$ & $21(61.8)$ & \\
\hline 2 & $11(33.3)$ & $22(66.7)$ & \\
\hline 3 & $0(0.0)$ & $0(0.0)$ & \\
\hline \multicolumn{4}{|l|}{ Parameter } \\
\hline $\begin{array}{l}\text { Mean } \mathrm{Hb} \text { in } \mathrm{g} / \mathrm{dL} \\
\pm \mathrm{SD}\end{array}$ & $10.5 \pm 2.21$ & $9.1 \pm 2.16$ & 0.17 \\
\hline $\begin{array}{l}\text { Mean WBCs in } \\
\times 10^{9} / \mathrm{L} \pm \mathrm{SD}\end{array}$ & $18.9 \pm 13.89$ & $10.7 \pm 8.12$ & 0.002 \\
\hline $\begin{array}{l}\text { Mean platelets in } \\
\times 10^{9} / \mathrm{L} \pm \mathrm{SD}\end{array}$ & $263.0 \pm 128.9$ & $229.2 \pm 234.9$ & 0.501 \\
\hline $\begin{array}{l}\text { Mean peripheral } \\
\text { blasts in } \% \pm \text { SD }\end{array}$ & $2.0 \pm 2.85$ & $1.2 \pm 2.11$ & 0.177 \\
\hline $\begin{array}{l}\text { Mean LDH in } \\
\text { U/L } \pm \text { SD }\end{array}$ & $\begin{array}{l}1125.4 \pm \\
618.6\end{array}$ & $909.7 \pm 560.8$ & 0.135 \\
\hline $\begin{array}{l}\text { Grade of marrow } \\
\text { fibrosis }\end{array}$ & & & 0.570 \\
\hline 0 & $3(50.0)$ & $3(50.0)$ & \\
\hline 1 & $11(44.0)$ & $14(56.0)$ & \\
\hline 2 & $8(29.6)$ & $19(70.4)$ & \\
\hline 3 & $4(28.6)$ & $10(71.4)$ & \\
\hline $\begin{array}{l}\text { Mean spleen } \\
\text { volume in } \mathrm{cm}^{3} \\
\pm \mathrm{SD}\end{array}$ & $934.3 \pm 423.3$ & $764.4 \pm 388.6$ & 0.092 \\
\hline $\begin{array}{l}\text { Constitutional } \\
\text { symptoms }\end{array}$ & & & 0.225 \\
\hline Yes & $20(40.8)$ & $29(59.2)$ & \\
\hline No & $6(26.1)$ & 17 (73.9) & \\
\hline $\begin{array}{l}\text { BAT = best available the } \\
E C O G-P S=\text { Eastern } \\
\text { Hb = haemoglobin; } S D \\
L D H=\text { lactate dehydr }\end{array}$ & $\begin{array}{l}\text { yy; IPSS = Intern } \\
\text { perative Oncol } \\
\text { standard devic } \\
\text { enase. }\end{array}$ & $\begin{array}{l}\text { onal Prognostic } \\
y \text { Group Perforn } \\
\text { ion; } W B C=\text { wh }\end{array}$ & $\begin{array}{l}\text { ring System } \\
\text { nce Status; } \\
\text { blood cell; }\end{array}$ \\
\hline
\end{tabular}

to treat anaemia in asymptomatic patients using hydroxyurea as a cytoreductive drug for splenomegaly and constitutional symptoms and employing splenic radiation and splenectomy. ${ }^{7}$ However, all of these means of conventional therapies remain palliative and aim to improve the patients' quality of life.

Ruxolitinib was approved for the first time in November 2011 in the United States for the treatment of intermediate or high-risk MF patients. In Europe, it was approved for treating splenomegaly and MFrelated symptoms. ${ }^{8}$ The initial ruxolitinib approval was based on the results of two clinical trials, COMFORT-I and COMFORT-II. ${ }^{9,10}$ Although ruxolitinib exerts a dramatic therapeutic effect, it seems to be temporary as symptoms rapidly return with the splenic size increasing soon after the drug is stopped or its dose reduced. ${ }^{11}$

In this context, this study aimed to compare the effectiveness of ruxolitinib to the other best available treatment (BAT) options in MF patients.

\section{Methods}

In this study, patients with primary MF were retrospectively analysed. The patients were diagnosed and treated at Nanakali Hemato-Oncology Teaching Centre in Erbil, Iraqi Kurdistan, from January 2012 to January 2018. Clinical and laboratory data were retrieved from the patients' hospital records. The diagnosis and staging of MF were based on World Health Organization criteria. ${ }^{6,12}$ The complete blood picture with circulating blast cell percentage and serum lactate dehydrogenase ( $\mathrm{LDH})$, recorded both at the baseline and after 24 weeks of follow-up, was checked. All patients underwent bone marrow biopsies for the assessment of the grade of fibrosis. Spleen size was measured by ultrasound at the time of presentation and 24 weeks after treatment for all patients. The patients were analysed only for JAK2 mutation while the MPL and CALR mutations were not analysed due to lack of facilities. The Eastern Cooperative Oncology Group Performance Status (ECOG-PS) was determined for the included patients. The IPSS category was determined based on the presence of the previously mentioned adverse prognostic factors at the time of presentation. Patients with incomplete data or no proper follow-up were excluded from this study.

The recruited patients were divided into two groups according to the type of treatment they received: the ruxolitinib group included 26 patients treated with ruxolitinib and the other group included the remaining 46 patients who received the BAT including danazol, hydroxyurea and blood transfusion. 
The starting dose of ruxolitinib depended on the baseline platelet count. Patients with a platelet count of $100-200 \times 10^{9} / \mathrm{L}$ were given $15 \mathrm{mg}$ twice daily and those with a platelet count $>200 \times 10^{9} / \mathrm{L}$ received $20 \mathrm{mg}$ twice daily. The dose was adjusted for lack of efficacy or excess toxicity as specified in the COMFORT-I study. ${ }^{9}$ Follow-up was done on a weekly basis in the first month, then every other week for the next two months and monthly thereafter. A clinical and haematological evaluation was conducted at each follow-up visit and an abdominal sonogram was performed monthly. Common side effects were haematological (mild anaemia or thrombocytopaenia) while non-haematological side effects (dizziness, headache, fatigue and bloating) were mild and necessitated dose modification.

The response to treatment and the outcome of the disease were recorded. Progression-free survival (PFS) and overall survival (OS) were estimated. In this regard, PFS is the time from treatment initiation until disease progression or worsening while OS is the duration of patient survival from the time of treatment initiation; OS is a universally accepted direct measure of clinical benefit.

Statistical Package for the Social Sciences (SPSS), Version 22.0 (IBM, Armonk, NY, USA), was used for data analysis. The chi-squared test of association was used to compare proportions. Paired sample t-test was used to compare the mean $\mathrm{Hb}$, platelets, LDH levels and spleen size of the patients in both the groups before and after treatment. The five-year OS and PFS estimates were calculated using the life table method and Cox multivariate analysis was performed to detect the risk factors that affected OS and PFS. The KaplanMeier method was used to plot the survival curves. $P$ $\leq 0.05$ was considered statistically significant.

This study was approved by the Scientific and Ethical Committees of the College of Medicine, Hawler Medical University in Erbil, Iraq (No.MD 305).

\section{Results}

The records of a total of 72 patients were retrospectively examined for this study. The mean age of the studied patients was $59.7 \pm 12.4$ years. Males constituted $52.8 \%$ of the sample population and the male-tofemale ratio was 1.1:1. The median time of follow-up was 43 months, with the follow-up time ranging from 15 to 98 months. The majority of the patients in both treatment groups combined ( $n=46,63.9 \%)$ were in the high and the intermediate- 2 risk IPSS groups and the ECOG-PS was one and two in 67 patients (93.1\%) in total. Statistical analysis demonstrated no significant differences between the two groups regarding baseline clinical and laboratory characteristics except for the WBC count which was significantly higher in the ruxolitinib group $(P=0.002)$. Constitutional symptoms were present in 49 (68.1\%) patients in total (from both groups), but no significant difference was present between the two $(P=0.225)$ [Table 1].

Concerning the efficacy of treatment, MF patients who received ruxolitinib had a significant regression in spleen volume compared to patients in the BAT group $(P<0.001)$. The remaining parameters of $\mathrm{Hb}$, WBC and platelet levels did not show any significant differences. The mean LDH level reduced following ruxolitinib administration; however, the difference was not statistically significant when compared to the BAT group $(P=0.125)$ [Table 2].

The five-year OS and the PFS rates among MF patients were $41 \%$ and $67 \%$, respectively. The OS rate of the ruxolitinib group was significantly higher than that of the BAT group (53\% versus $26 \% ; P=0.008$ ) [Table 3 , Figure 1]. Similarly, the PFS rate was higher in the ruxolitinib group; however, it did not reach a statistically significant level $(P=0.073)$ [Table 3, Figure 2].

The IPSS significantly affected both OS and PFS in the BAT cohort ( $P=0.004$ and $P=0.001$, respectively) but not in the ruxolitinib cohort. The OS rate related

Table 2: Comparison of the efficacy of treatment across two groups of patients (treated using either ruxolitinib or the best available therapy) with primary myelofibrosis

\begin{tabular}{|c|c|c|c|c|c|}
\hline \multirow[t]{2}{*}{ Parameter } & \multicolumn{2}{|c|}{ Ruxolitinib } & \multicolumn{2}{|c|}{ BAT } & \multirow[t]{2}{*}{$P$ value } \\
\hline & Before treatment & After treatment & Before treatment & After treatment & \\
\hline Mean $\mathrm{Hb}$ in $\mathrm{g} / \mathrm{dL} \pm \mathrm{SD}$ & $10.5 \pm 2.21$ & $9.5 \pm 3.04$ & $9.1 \pm 2.16$ & $9.4 \pm 2.64$ & 0.097 \\
\hline Mean WBC in $\times 10^{9} / \mathrm{L} \pm \mathrm{SD}$ & $18.9 \pm 13.89$ & $17.6 \pm 15.49$ & $10.7 \pm 8.12$ & $15.0 \pm 17.32$ & 0.136 \\
\hline $\begin{array}{l}\text { Mean platelets in } \times 10^{9} / \mathrm{L} \\
\pm \mathrm{SD}\end{array}$ & $263.0 \pm 128.9$ & $192.1 \pm 117.75$ & $229.2 \pm 234.9$ & $364.7 \pm 917.65$ & 0.303 \\
\hline Mean $\mathrm{LDH}$ in $\mathrm{U} / \mathrm{L} \pm \mathrm{SD}$ & $1125.4 \pm 618.6$ & $1058.2 \pm 585.80$ & $909.7 \pm 560.8$ & $998.4 \pm 501.62$ & 0.125 \\
\hline $\begin{array}{l}\text { Mean spleen volume in } \mathrm{cm}^{3} \\
\pm \mathrm{SD}\end{array}$ & $934.3 \pm 423.3$ & $616.7 \pm 384.58$ & $764.4 \pm 388.6$ & $894.0 \pm 563.29$ & $<0.001$ \\
\hline
\end{tabular}


Table 3: Survival rates (overall survival and progressionfree survival) across two groups of patients (treated using either ruxolitinib or the best available therapy) with primary myelofibrosis

$\begin{array}{lcccc}\begin{array}{l}\text { Type of } \\ \text { Treatment }\end{array} & \begin{array}{c}\text { OS } \\ \text { in } \% \\ (\mathbf{9 5 \% C I})\end{array} & \begin{array}{c}\boldsymbol{P} \\ \text { value }\end{array} & \begin{array}{c}\text { PFS } \\ \text { in } \% \\ (\mathbf{9 5 \% C I})\end{array} & \begin{array}{c}\boldsymbol{P} \\ \text { value }\end{array} \\ \text { Ruxolitinib } & 53 & 0.008 & 79 & 0.073 \\ & (33.8-72.2) & & (63.3-94.7) & \\ \text { BAT } & 26 & & 55 & \\ & (13.3-38.7) & & (40.6-69.4) & \end{array}$

$O S=$ overall survival; $C I=$ confidence interval; $P F S=$ progression - free survival; $B A T=$ best available therapy.

$* P \leq 0.05$ was considered statistically significant.

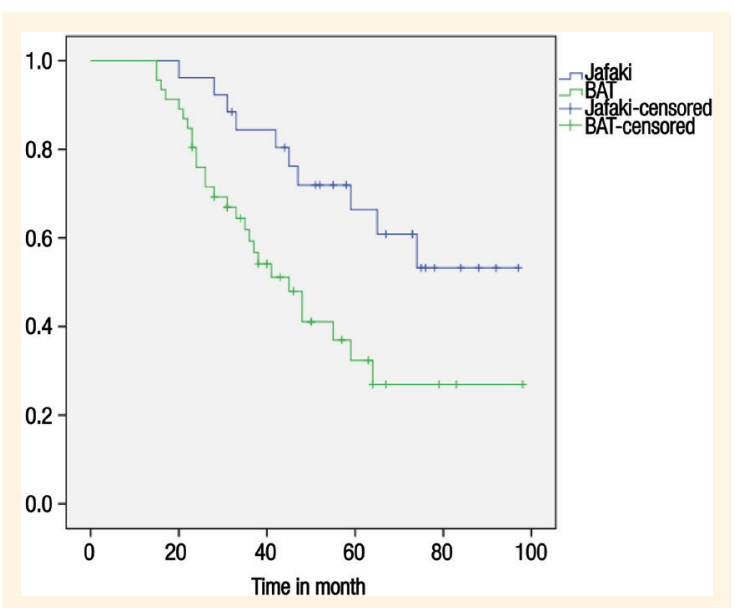

Figure 1: Kaplan-Meier cumulative survival curve showing the overall survival rates in relation to the type of treatment among a group of patients with primary myelofibrosis.

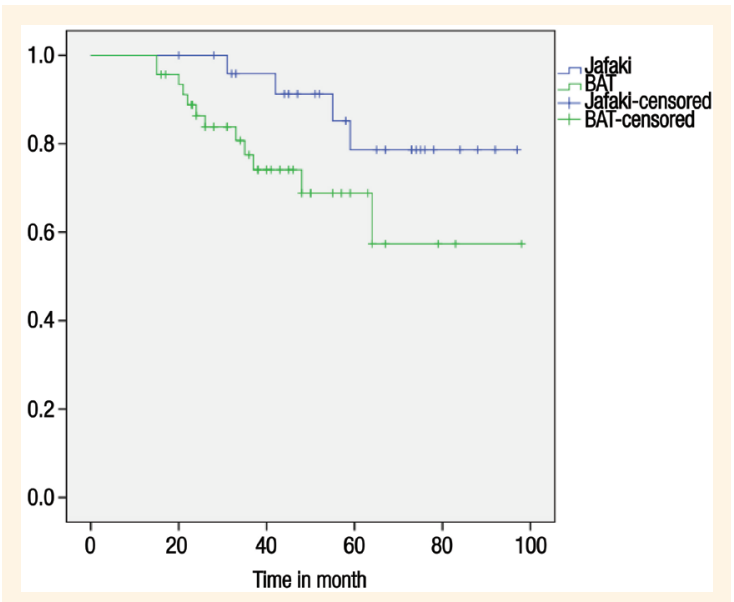

Figure 2: Kaplan-Meier cumulative survival curve showing the progression-free survival rates in relation to the type of treatment among a group of patients with primary myelofibrosis.

significantly to the ECOG-PS in both groups. No significant correlation was found between survival rates and the means of WBC, platelet and LDH levels and spleen volume in both groups. The percentage of peripheral blast cells significantly affected the PFS in both cohorts $(P=0.013$ and $P=0.004$, respectively) and the OS in the BAT cohort only $(P=0.001)$. The mean $\mathrm{Hb}$ level had a significant effect on OS in the BAT group only $(P=0.018)$ [Table 4 ].

The Cox multivariate analysis of the prognostic factors demonstrated that only the type of treatment had a significant association with the OS (hazard ratio $=9.16,95 \%$ CI: 2.81-29.86), while the age of the patients, type of the treatment, $\mathrm{Hb}$ level, platelet count and high risk as per the IPSS were significantly associated with PFS [Table 5].

\section{Discussion}

Ruxolitinib is a JAK inhibitor that has been approved for the treatment of patients with MF. In particular, the Food and Drug Administration (FDA) has approved it for intermediate and high-risk MF patients whereas the European Medicines Agency (EMA) has approved it for the treatment of splenomegaly and/or constitutional symptoms, irrespective of the patient's risk group. ${ }^{8}$

The median age of the primary MF patients was 60 years and males constituted 53\% of the included sample. It is noteworthy that according to the literature, MF in many other parts of the world occurs later in life. ${ }^{9,13,14}$ The majority of the patients in this study were in the intermediate- 2 and high-risk groups and most of their ECOG-PS scores were one and two. Two-thirds of the patients had constitutional symptoms at the time of diagnosis, a finding that is in alignment with previous studies. ${ }^{6,15}$

The analysis revealed that ruxolitinib has a significant effect on the regression of the spleen size after 24 weeks of follow-up. Conversely, the mean spleen size increased after treatment in the BAT cohort and these data are comparable to many other studies.9,10,11,16,17 Needless to say, a reduction in the size of the spleen will alleviate the patients' abdominal complaints and will, hence, improve the patients' quality of life. Furthermore, a study found that a reduction in spleen size following ruxolitinib administration is correlated with higher survival. ${ }^{15}$ However, the findings of this study could not note such a correlation among the patients, probably due to the small sample size.

On the other hand, patients who received treatment with ruxolitinib experienced anaemia and a greater reduction in platelet and WBC count compared to those who received the BAT; however, the reduction in the haematological parameters did not reach a statistically significant level. These findings were expected and are attributed to the mechanism of 
Table 4: The effect of clinical parameters on the overall survival and progression-free survival rates across two groups of patients (treated using either ruxolitinib or the best available therapy) with primary myelofibrosis

\begin{tabular}{|c|c|c|c|c|c|c|c|c|}
\hline \multirow[t]{2}{*}{ Parameter } & \multicolumn{4}{|c|}{ Ruxolitinib } & \multicolumn{4}{|c|}{ BAT } \\
\hline & OS in $\%$ & $P$ value & PFS in \% & $P$ value & OS in $\%$ & $P$ value & PFS in $\%$ & $P$ value \\
\hline Age & & 0.328 & & 0.872 & & 0.090 & & 0.228 \\
\hline$<60$ years & 67 & & 79 & & 44 & & 42 & \\
\hline$\geq 60$ years & 42 & & 78 & & 16 & & 62 & \\
\hline Gender & & 0.166 & & 0.340 & & 0.727 & & 0.337 \\
\hline Male & 74 & & 71 & & 28 & & 46 & \\
\hline Female & 38 & & 89 & & 22 & & 67 & \\
\hline IPSS & & 0.395 & & 0.121 & & 0.004 & & 0.001 \\
\hline High risk & 27 & & 55 & & 7 & & 25 & \\
\hline Intermediate-2 & 61 & & 100 & & 26 & & 100 & \\
\hline Intermediate-1 & 57 & & 100 & & 0 & & 87 & \\
\hline Low risk & 100 & & 100 & & 75 & & 58 & \\
\hline ECOG-PS & & 0.003 & & 0.140 & & 0.003 & & 0.125 \\
\hline 0 & 50 & & 100 & & 100 & & 50 & \\
\hline 1 & 92 & & 89 & & 37 & & 72 & \\
\hline 2 & 11 & & 58 & & 6 & & 56 & \\
\hline Mean $\mathrm{Hb}$ in $\mathrm{g} / \mathrm{dL}$ & & 0.670 & & 0.068 & & 0.018 & & 0.127 \\
\hline$<10$ & 47 & & 64 & & 20 & & 63 & \\
\hline$\geq 10$ & 62 & & 100 & & 37 & & 55 & \\
\hline Mean $\mathrm{WBC}$ in $\times 10^{9} / \mathrm{L}$ & & 0.780 & & 0.521 & & 0.548 & & 0.980 \\
\hline$\leq 11$ & 55 & & 88 & & 25 & & 68 & \\
\hline$>11$ & 55 & & 73 & & 32 & & 53 & \\
\hline Mean platelets in $\times 10^{9} / \mathrm{L}$ & & 0.143 & & 0.760 & & 0.666 & & 0.544 \\
\hline$<100$ & 0 & & 100 & & 30 & & 61 & \\
\hline$\geq 100$ & 56 & & 79 & & 24 & & 49 & \\
\hline $\begin{array}{l}\text { Mean peripheral blasts } \\
\text { in } \%\end{array}$ & & 0.407 & & 0.013 & & 0.001 & & 0.004 \\
\hline$=0$ & 64 & & 100 & & 42 & & 69 & \\
\hline$\geq 1$ & 36 & & 54 & & 7 & & 34 & \\
\hline Mean LDH in U/L & & 0.688 & & 0.413 & & 0.077 & & 0.431 \\
\hline$\leq 450$ & 75 & & 100 & & 75 & & 75 & \\
\hline$>450$ & 51 & & 76 & & 21 & & 51 & \\
\hline $\begin{array}{l}\text { Mean spleen volume in } \\
\mathbf{c m}^{3}\end{array}$ & & 0.262 & & 0.526 & & 0.115 & & 0.349 \\
\hline$\leq 324$ & 33 & & 100 & & 100 & & 100 & \\
\hline$>324$ & 56 & & 78 & & 22 & & 54 & \\
\hline
\end{tabular}

BAT = best available therapy; OS = overall survival; PFS = progression-free survival; IPSS = International Prognostic Scoring System; ECOG-PS = Eastern Cooperative Oncology Group Performance Status; Hb = haemoglobin; WBC = white blood cell; $L D H=$ lactate dehydrogenase.

action of ruxolitinib. Similar observations have been made in many other reports. ${ }^{4,10,18}$

A very high LDH level is well known as being an independent predictor of shorter OS and leukaemiafree survival in primary MF. ${ }^{19}$ In the current study, no significant correlation between the LDH level and survival rates was observed; however, the mean serum
LDH level was elevated in the BAT cohort, while it was only slightly (not statistically significant) reduced after ruxolitinib administration. This finding aligned with another study conducted in Taiwan, which reported that none of the MF patients had normalised LDH levels after treatment with ruxolitinib. ${ }^{20}$ 
Table 5: Cox analysis of prognostic factors for survival among patients with primary myelofibrosis

\begin{tabular}{lcccc} 
Factor & \multicolumn{2}{c}{ OS } & \multicolumn{2}{c}{ PFS } \\
& $\begin{array}{c}\boldsymbol{P} \\
\text { value }\end{array}$ & $\begin{array}{c}\text { Hazard } \\
\text { ratio } \\
(\mathbf{9 5 \%} \mathrm{CI})\end{array}$ & $\begin{array}{c}\boldsymbol{P} \\
\text { value }\end{array}$ & $\begin{array}{c}\text { Hazard ratio } \\
(\mathbf{9 5 \%} \mathrm{CI})\end{array}$ \\
\hline Age & 0.187 & $\begin{array}{c}0.97 \\
(0.94-1.01)\end{array}$ & 0.008 & $\begin{array}{c}0.85 \\
(0.75-0.96)\end{array}$
\end{tabular}

Gender

Male

Female

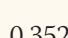

1

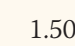

$(0.64-3.52)$

0.185

0.24

(0.03-1.96)

Ruxolitinib

1

BAT

$0.000 \quad 9.16$

(2.81-29.86)

0.047

0.016

Hb level

$\begin{array}{lc}0.144 & 0.81 \\ & (0.61-1.07\end{array}$

0.016

WBC

0.288

1.02
$(0.98-1.07)$

0.677

1.00

0.02

Platelet

0.127

(1.00-1.00)

Blasts

0.223

1.12
$(0.93-1.35)$

0.687

LDH

0.434

(1.00-1.00)

Spleen

0.14

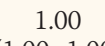

(1.00-1.00)

1

13.88

(1.04-185.96)

0.34

0.98

(0.91-1.06)

1.01

(1.00-1.01)

0.93

(0.65-1.33)

$0.073 \quad 1.00$

(1.00-1.00)

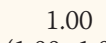

(1.00-1.00)

IPSS

Low

Inter-

mediate-1

Inter-

mediate-2

High

0.152

1

3.43

(0.51-23.23)

0.602

0.36

(0.01-16.98)

ECOG-PS

0

1

1

0.315

0.26
$0.02-3.54$

0.237

1.33

(0.09-19.28)
(0.14-0.82)

did not find any survival advantage for ruxolitinib and they related this discrepancy in ruxolitinib's effect on the survival state to lack of biological evidence (the attainment of remission or reversal of bone marrow fibrosis) and lack of a molecular or cytogenetic response. ${ }^{8,23}$

Additionally, this study found that some of the patients' characteristics affected the survival rate for MF. The ECOG-PS had an impact on the OS among both therapeutic groups and this is in line with other studies on the effect of ECOG on survival state in $\mathrm{MF}^{24,25}$ Cox multivariate analysis demonstrated that the age of patients, high risk as per the IPSS and some of the lab findings ( $\mathrm{Hb}$ level and platelet count) also affected PFS. The age of the patient and $\mathrm{Hb}$ level are well-known risk factors from the widely used prognostic scores as per the IPSS and DIPSS. ${ }^{6}$ Additionally, a low platelet count is a poor prognostic factor in MF as shown in other studies and the DIPSSPlus classification. ${ }^{26,27}$

This study is not without limitations. One of the limitations was the relatively small sample which was also retrospectively analysed. Additionally, genetic testing was limited to the JAK2 mutation analysis.

\section{Conclusion}

The findings of the current study revealed that treatment of MF with ruxolitinib has a significant impact on reducing splenic size; in return, this will improve the quality of life and the survival outcomes in patients with myelofibrosis. Therefore, the treatment of MF with ruxolitinib has the potential to improve the clinical course of this disease.

\section{AUTHORS' CONTRIBUTIONS}

$\mathrm{KMH}$ and AYE collected the data. NPS performed the statistical analysis. KMH drafted the manuscript. All authors approved the final version of the manuscript.

\section{FUNDING}

No funding was received for this study.

\section{CONFLICTS OF INTEREST}

$O S=$ overall survival $;$ PFS = progression-free survival $; C I=$ confidence interval; $B A T=$ best available therapy; $H b=$ haemoglobin; $W B C=$ white blood cell; $L D H=$ lactate dehydrogenase; IPSS = International Prognostic Scoring System; ECOG-PS = Eastern Cooperative Oncology Group Performance Status

Furthermore, the findings of this study demonstrated that ruxolitinib could affect the survival outcomes, as indicated by the improved OS and PFS of the ruxolitinib group of MF patients. Many clinical studies using data from the COMFORT studies have reported similar results. ${ }^{11,21,22}$ On the other hand, Tefferi et al.
The authors declare no conflicts of interest.

\section{References}

1. Rampal R, Al-Shahrour F, Abdel-Wahab O, Patel JP, Brunel JP, Mermel $\mathrm{CH}$, et al. Integrated genomic analysis illustrates the central role of JAK-STAT pathway activation in myeloproliferative neoplasm pathogenesis. Blood 2014; 123:e123-33. https://doi. org/10.1182/blood-2014-02-554634. 
2. Mesa RA, Verstovsek S, Cervantes F, Barosi G, Reilly JT, Dupriez B, et al. Primary myelofibrosis (PMF), post polycythemia vera myelofibrosis (post-PV MF), post essential thrombocythemia myelofibrosis (post-ET MF), blast phase PMF (PMF-BP): Consensus on terminology by the international working group for myelofibrosis research and treatment (IWG-MRT). Leuk Res 2007; 31:737-40. https://doi.org/10.1016/j.leukres.2006.12.002.

3. Klampfl T, Gisslinger H, Harutyunyan AS, Nivarthi H, Rumi E, Milosevic JD, et al. Somatic mutations of calreticulin in myeloproliferative neoplasms. N Engl J Med 2013; 369:2379-90. https://doi.org/10.1056/NEJMoa1311347.

4. Verstovsek S, Kantarjian H, Mesa RA, Pardanani AD, CortesFranco J, Thomas DA, et al. Safety and efficacy of INCB018424, a JAK1 and JAK2 inhibitor, in myelofibrosis. N Engl J Med 2010; 363:1117-27. https://doi.org/10.1056/NEJMoa1002028.

5. Tefferi A. Myelofibrosis with myeloid metaplasia. N Engl Med 2000; 342:1255-65. https://doi.org/10.1056/NEJM2000 04273421706

6. Cervantes F, Dupriez B, Pereira A, Passamonti F, Reilly JT, Morra E, et al. New prognostic scoring system for primary myelofibrosis based on a study of the International Working Group for Myelofibrosis Research and Treatment. Blood 2009; 113:2895-901. https://doi.org/10.1182/blood-2008-07-170449.

7. Cervantes F. How Itreat myelofibrosis. Blood 2014; 124:2635-42. https://doi.org/10.1182/blood-2014-07-575373.

8. Cervantes F, Pereira A. Does ruxolitinib prolong the survival of patients with myelofibrosis? Blood 2017; 129:832-7. https:// doi.org/10.1182/blood-2016-11-731604.

9. Verstovsek S, Mesa RA, Gotlib J, Levy RS, Gupta V, DiPersio JF, et al. A double-blind placebo-controlled trial of ruxolitinib for myelofibrosis. N Engl J Med 2012; 366:799-807. https://doi. org/10.1056/NEJMoa1110557.

10. Harrison C, Kiladjian J-J, Al-Ali HK, Gisslinger H, Waltzman R, Stalbovskaya V, et al. JAK inhibition with ruxolitinib versus best available therapy for myelofibrosis. N Engl J Med 2012; 366:787-98. https://doi.org/10.1056/NEJMoa1110556.

11. Bryan JC, Verstovsek S. Overcoming treatment challenges in myelofibrosis and polycythemia vera: The role of ruxolitinib. Cancer Chemother Pharmacol 2016; 77:1125-42. https://doi. org/10.1007/s00280-016-3012-z.

12. Arber DA, Orazi A, Hasserjian R, Thiele J, Borowitz MJ Le Beau MM, et al. The 2016 revision to the World Health Organization classification of myeloid neoplasms and acute leukemia. Blood 2016; 127:2391-405. https://doi.org/10.1182/ blood-2016-03-643544

13. Iurlo A, Cattaneo D. Treatment of myelofibrosis: Old and new strategies. Clin Med Insights Blood Disord 2017; 10:1-10. https://doi.org/10.1177/1179545X17695233.

14. Benites BD, Lima CSC, Lorand-Metze I, Delamain MT, Oliveira GB, de Almeida D, et al. Primary myelofibrosis: Risk stratification by IPSS identifies patients with poor clinical outcome. Clinics (Sao Paulo) 2013; 68:339-43. https://doi. org/10.6061/clinics/2013(03)oa09.

15. Takenaka K, Shimoda K, Akashi K. Recent advances in the diagnosis and management of primary myelofibrosis. Korean J Intern Med 2018; 33:679-90. https://doi.org/10.3904/kjim.2018.033.
16. Kantarjian HM, Silver RT, Komrokji RS, Mesa RA, Tacke R, Harrison CN. Ruxolitinib for myelofibrosis-An update of its clinical effects. Clin Lymphoma Myeloma Leuk 2013; 13:638-45. https://10.1016/j.clml.2013.09.006.

17. Verstovsek S, Mesa RA, Gotlib J, Gupta V, DiPersio J, Catalano I, et al. Long-term treatment with ruxolitinib for patients with myelofibrosis: 5-year update from the randomized, doubleblind, placebo-controlled, phase 3 COMFORT-I trial. J Hematol Oncol 2017; 10:55. https://10.1186/s13045-017-0417-z.

18. Shi JG, Chen X, McGee RF, Landman RR, Emm T, Lo Y, et al. The pharmacokinetics, pharmacodynamics, and safety of orally dosed INCB018424 phosphate in healthy volunteers. J Clin Pharmacol 2011; 51:1644-54. https://doi.org/10.1177/ 0091270010389469.

19. Shah S, Mudireddy M, Hanson CA, Ketterling R, Gangat N, Pardanani A, et al. Marked elevation of serum lactate dehydrogenase in primary myelofibrosis: Clinical and prognostic correlates. Blood Cancer J 2017; 7:657. https://doi.org/10.1038/ s41408-017-0024-9.

20. Chen Y-Y, Huang C-E, Lee K-D, Chen C-C. Clinical efficacy and safety of ruxolitinib in the management of myelofibrosis: A single institution experience in Taiwan. Hematology 2016; 21:3-9. https://doi.org/10.1179/1607845415Y.0000000036.

21. Verstovsek S, Kantarjian HM, Estrov Z, Cortes JE, Thomas DA, Kadia T, et al. Long-term outcomes of 107 patients with myelofibrosis receiving JAK1/JAK2 inhibitor ruxolitinib: Survival advantage in comparison to matched historical controls. Blood 2012; 120:1202-9. https://doi.org/10.1182/blood-2012-02-414631.

22. Schain F, Vago E, Song C, He J, Lewing J, Löfgren C, et al. Survival outcomes in myelofibrosis patients treated with ruxolitinib: A population-based cohort study in Sweden and Norway. Eur J Haematol 2019; 103:614-19. https://doi.org/10.1111/ ejh.13330.

23. Tefferi A, Litzow MR, Pardanani A. Long-term outcome of treatment with ruxolitinib in myelofibrosis. N Engl J Med 2011; 365:1455-7. https://doi.org/10.1056/NEJMc1109555.

24. Newberry KJ, Naqvi K, Nguyen KT, Cardenas-Turanzas M, Tanaka MF, Pierce S, et al. Comorbidities predict worse prognosis in patients with primary myelofibrosis. Cancer 2014; 120:2996-3002. https://doi.org/10.1002/cncr.28857.

25. Bartoszko J, Panzarella T, McNamara CJ, Lau A, Schimmer AD, Schuh AC, et al. Distribution and impact of comorbidities on survival and leukemic transformation in myeloproliferative neoplasm-associated myelofibrosis: A retrospective cohort study. Clin Lymphoma Myeloma Leuk 2017; 17:774-81. https:// doi.org/10.1016/j.clml.2017.06.031.

26. Tam CS, Kantarjian H, Cortes J, Lynn A, Pierce S, Zhou L, et al. Dynamic model for predicting death within 12 months in patients with primary or post-polycythemia vera/essential thrombocythemia myelofibrosis. J Clin Oncol 2009; 27:5587-93. https://10.1200/JCO.2009.22.8833.

27. Gangat N, Caramazza D, Vaidya R, George G, Begna K, Schwager S, et al. DIPSS plus: A refined Dynamic International Prognostic Scoring System for primary myelofibrosis that incorporates prognostic information from karyotype, platelet count, and transfusion status. J Clin Oncol 2011; 29:392-7. https://doi.org/10.1200/JCO.2010.32.2446. 